\title{
The research and practice of the "tripartite education" mode based on modern apprenticeship
}

\author{
Yaomin $\mathrm{Hu}^{1}$, Dongxiu $\mathrm{Yu}^{2}$ \\ 1. School of Information Engineering , Guangzhou Panyu Polytechnic, Guangzhou \\ 511483, China \\ 2. University of Electronic Science and Technology of China,Zhongshan Institute, \\ Zhongshan, Guangdong, 528402, China
}

\begin{abstract}
The modern apprenticeship is a education mode to train more innovative practical technicians, which can provide an effective way for "Supporting the will and wisdom". This paper explored the "tripartite education" mode based on modern apprenticeship of computer application technology, from the aspects of cultivation mode design, enrollment mode, cultivation scheme design and cultivation methods, and then summarized the effect after implementation.
\end{abstract}

Keywords: modern apprenticeship, supporting the will \& supporting the intelligence, educational mode, practice

\section{Introduction}

Modern apprenticeship is an innovative technology and skill talent training model, which can provide a way to promote the interactive development of the vocational education system and the labor employment system, and to open up and broaden the training and growth channels of technology and skill talents ${ }^{[1]}$. The modern apprenticeship system has become one of the directions of the reform of the talent training model in domestic higher vocational education. Schools, enterprises, and governments 
in some areas have actively participated in its theoretical research and practical exploration ${ }^{[2-7]}$. Zhang Ronggui and others took the automobile major of Fujian Ship Administration and Transportation Vocational College as an example, explored the problems in the joint training process of school and

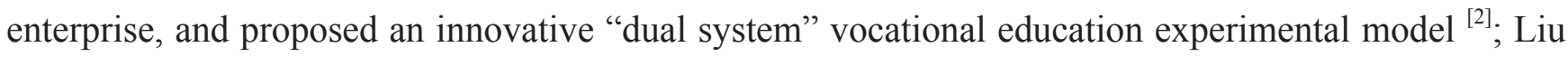
Ruiyao took the Zhejiang University of Finance and Economics Dongfang College International Trade Take professional as an example, and propose a cross-border e-commerce talent training model based on the modern apprenticeship system of "three stages of progression" and "three divisions together" ${ }^{[3]}$. How to effectively coordinate the participation and participation methods of the school, government, and enterprise, and promote the improvement of students' comprehensive skills and comprehensive literacy cultivated by modern apprenticeship, has become a bottleneck problem in whether modern apprenticeship can be implemented as a way of vocational education reform and innovation. In response to the above-mentioned problems, this paper puts forward the talent training mode of "tripartite education" based on modern apprenticeship. Taking the modern apprenticeship class of computer application major in Guangzhou Panyu Polytechnic as an example, this paper puts forward solutions to the problems existing in the modern apprenticeship and " tripartite education " talent training mode, provides new ideas for the pilot implementation and promotion of modern apprenticeship, and provides new experience for the national poverty alleviation work.

\section{Proposal of the "Tripartite Education" talent training model based on modern apprenticeship}

\subsection{Background analysis}

The participating enterprise of the modern apprenticeship class of computer application major of Guangzhou Panyu Polytechnic is Meizhou Guangmei Information Technology Co., Ltd., and the participating government is Guangzhou Education Bureau and Meizhou Education Bureau. Meizhou City is a relatively poor area in Guangdong Province. Guangmei Industrial Park was co-built by Guangzhou's counterpart to help Meizhou. Meizhou Guangmei Information Technology Co., Ltd. is one of the core enterprises in Guangmei Industrial Park. The company is a state-owned enterprise, positioned as with big data processing business and information service for Guangmei Industrial Park. Enterprises need a large number of innovative technical talents for big data processing, park network construction, and information system construction. Meizhou is far away from the Pearl River Delta, and limited by local educational resources and economic development, there are certain difficulties in recruitment, which seriously affects the operation status, industrial transformation and upgrading, and innovation capabilities of Guangmei Industrial Park. It is expected to jointly build a modern apprenticeship talent training model to effectively solve: Improve the scientific literacy, professionalism and vocational skills of secondary vocational students in poverty-stricken areas, and simultaneously 
solve the employment problem; Solve the problem of insufficient information technology personnel and recruitment difficulties in Guangmei Industrial Park .

Based on the above background, with the aim of cultivating talents with innovative skills, "tripartite education" talent training model based on the modern apprenticeship is proposed, which consists of government, school and enterprise.

1.2 "Tripartite education" talent training model based on modern apprenticeship

Based on the modern apprenticeship system of politics, schools, and enterprises, the "tripartite education " talent training model uses local secondary vocational and high school graduates in Meizhou as the source of students. The government provides tuition reduction and exemption, urban settlement and other policies, and sends cadres to serve as head teachers during the training process, school teachers and business masters are both tutors in teaching. Government supports the integration of resources of the school and the enterprise. The school provides professional tutors to complete the transmission of professional basic knowledge, and the enterprise provides enterprise masters to train job skills, the enterprise becomes the dominant role of talent training, and jointly implements the "triple education" Mode combined with work and learning. The mode is divided into three stages.

The first stage is to set a solid knowledge foundation and recognize careers. This stage is the first semester, mainly studying in school. The school formulates a specific teaching plan, implements curriculum intensive learning, and mainly learns professional basic knowledge. Enterprise masters regularly come to the school to exchange with students about corporate culture, professionalism, vocational skills, etc. The purpose is to allow students to have a clear understanding of the knowledge, abilities and standards required for the job, and to clarify the use of professional basic knowledge.

The second stage is to learn skills and experience careers. This stage is the second semester, focusing on studies in enterprise. Enterprise formulates specific learning plans and implements apprenticeship learning based on fixed jobs and assigned masters, mainly to learn the skills required for the jobs. College teachers formulate teaching plans according to jobs of students, convey the knowledge required for their jobs, build professional basic courses, and help them to improve job skills.

The third stage, innovative thinking trained on the jobs in the enterprise. This stage is the 3,4 semester. The apprentices learn and implement skills on the jobs, cultivate independent skills for the jobs, gradually master the core technology of the company, and complete the transformation of the status of apprentices to formal employees of the company. The college teachers provide the theoretical knowledge transfer of the core technology of the enterprise. From time to time, college teachers share and analyze the relevant technological frontiers with students to expand their horizons and thinking.

\section{The plan design of "Tripartite Education" talent training model}

Formulating a reasonable talent training plan is the key to the implementation of talent training, 
and a reasonable curriculum system is the core of ensuring the implementation of the talent training plan. Modern apprenticeship is an innovative education model that emphasizes the training of vocational skills and professional qualities. It is characterized by an integrated long-term mechanism for educating people, which can effectively improve the overall quality of production and service for frontline workers, and can solve the difficult problems in recruiting employees in enterprises. The design of its talent training program is that it needs to consider the needs of company. The objectives of Guangmei Information Technology Co., Ltd. are clearly divided into three categories: big data processing, network design and construction, and information system development.

According to goals put forward by the company, combined with the characteristics of students, the company and the school has formulated a "three-tier progressive" curriculum system to implement the innovative talent training program. The bottom-level is to consolidate theory Basic, middle-level is to strengthen professional skills, and the top-level is to meet vocational skill requirements and innovation awareness requirements for Guangmei Information Technology's development.

The bottom layer is designed to consolidate the basic theories, which is mainly to consolidate the foundation, cultivate students' basic computer knowledge. That is to lay a solid theoretical foundation for the training objectives of computer network design \& construction and information system development. The courses contain Java programming, Web front-end development technology, database system, computer network foundation, UI and image processing technology and other courses, and open communication on job recognition etc.

The middle level is designed to strengthen vocational skills, combined with the 3 types jobs of the enterprise, and clearly divided into three directions according to the objectives to cultivate students' professional skills, which includes big data processing, network design and implementation, and information system development. The courses include:Web application technology, frontend framework technology, Linux and server, network planning and design, mobile application development, big data foundation, Python language and data analysis courses, and the teaching of job skills for corporate instructors.

The top-level is designed as on-the-job training, which clearly points to the jobs of Guangmei Information Technology Co., Ltd., which is to cultivate good practical skills and innovative awareness. The courses served for it include: big data processing training, big data processing job rotation training, network engineering project training, network design and construction rotation training, software engineering project training, information system development rotation training and other practical courses, independent projects on the job Cultivation and innovation of new projects.

\section{Implementation of the "Tripartite Education" Talent Training Model}

\subsection{Admissions model}


The integration of enrolling workers and recruiting students is the basis for the modern apprenticeship ${ }^{[1]}$. "Tripartite education" is the core of modern apprenticeship in computer application technology, which is based on the principles of careful creation, precise training, individualized implementation, and targeted employment. Enrollment plans and implementation methods has formulated detailed to provide a guarantee for a stable source of students.

Recruiting students methods are carried out from two aspects. The first is the way of enrollment, which is closely integrated with poverty alleviation work. The main source of students is the Meizhou area. "Supporting the will and wisdom" department of Headquarters supporting Meizhou takes the lead to let the village cadres touch the village where they are, and find out the secondary vocational students and high school students who have graduated or are about to graduate, to publicize the training mode, recruitment method, charging method, settlement policy, business and development prospect of the modern apprenticeship class of computer application technology major in Guangzhou Panyu Polytechnic.

Secondly, the recruiting students method is flexible and diverse. Candidates need to be examined two parts: basic theory and hands-on practice. The certificate of students participating in the competition in the secondary vocational stage is an important basis for admission, and the training goals of Guangmei Information Technology Co., Ltd. are also considered. The basic knowledge of the theoretical examination is divided into five parts: the basics of computer general knowledge, the basics of programming language, the basics of web page, the basics of Internet using and the basics of Office using. Students with different training goals will get differentiated practice assessments. The student practice assessment of big data processing personnel is mainly the use of Office. The students of the campus network design and implementation personnel can choose to be assessed the construction of simple networks; the personnel of the park information system development can choose to be assessed programming or web page development.

\subsection{The allocation of teachers}

In the allocation of teachers, it is fully considered that students in modern apprenticeship class have certain professional basic knowledge, and more emphasis is placed on teachers' hands-on ability. Teachers' strong hands-on ability make students more convinced by teachers and encourage them to be more willing to learn actively. The school tries its best to choose teachers with corporate practical experience who have the dual identities of "teachers and masters", and requires teachers to demonstrate the whole process and then ask students to reproduce them. Enterprises need to recruit people with certain project experience and good expressions to play the role of "master and teacher", who can have strong hands-on ability and can better impart knowledge.

\subsection{Project-driven teaching}

Project-based teaching can make teaching visualized, operable, and more consistent in knowledge. 
The teaching of modern apprenticeship classes adopts project-based teaching. Class teachers use personal projects to share, segment, and standardize into professional teaching resources. For example, for a real software project, first divide the project into UI module, front-end module, back-end module, database module, etc., corresponding to UI and image processing technology, Web front-end development technology, Web application development technology, and database etc.. After students have a reflection on the overall effect of the project, they have a basic understanding of the application scenarios of basic theoretical knowledge and skills, which will stimulate students' strong interest in learning. The practice when explaining the basic theory is the recurrence of the corresponding skill points in the real project. Due to the authenticity of the projects, it eliminates students' doubts about their usefulness before learning. The goal of teacher teaching and student learning reach an agreement. After the completion of the agreement, the teacher changed the pure preaching method, and the students changed the aimless learning method, which really achieved the effect of getting twice the result with half the effort. Four weeks before the end of a course, the teacher arranged a course design project for classroom learning. The course design project is to refer to the real project in the course and simulate a similar project. After such a round of training, the students can eliminate most of the questions encountered in study. The progressive learning requirements and goals greatly cultivated students' professional skills and self-learning ability.

3.4 Job rotation of the enterprise

Another identity of modern apprenticeship students is a employee. In order to train the students, the company assigns students to the company's big data processing business group, park network construction group, and park information system development group according to the training goals and students' own choices. Each student has a corresponding enterprise skilled employee act as master. The master organizes the students around him, allows the students to have a period of observation and learning, familiarize themselves with the business process and basic business methods, and then guide the students to enter the project team. For example, the master of the information system development group will divide the software development task horizontally and allocate a small module for students to develop. During the development process, the project module that developed by master is used for reference. When problems encountered, questions can be put forward at any time, and the master is responsible for solving them. The master evaluates the students during the job rotation, and records the number of mistakes and the number of problems solved by the students in process, then comprehensively forms an evaluation report. The enterprise arranges jobs for students based on the comprehensive evaluation report of the master.

\section{The training effect of "Tripartite Education" talent training model}

Some students already have relevant vocational skills. There are a total of 55 students in the 
modern apprenticeship class, including 27 in the big data processing group, 12 in the network design and implementation group, and 16 in the information system development group. Now all the students in the big data processing group have entered the project group and are officially undertaking the project, while the network project design and implementation group is under the leadership of the corporate mentor to carry out the light current and networking work of the building in the park. The threshold for information system development is relatively high, the students in this group are growing relatively slowly. Most of the students are still following the project group of the corporate mentor and practice modules, and some students undertake part of the software black box testing. The overall satisfaction of the enterprise is relatively high, and all the students have signed formal employment contracts. Outstanding students in the class performed outstandingly. Xiao Ruihao have been assigned by the Guangmei Industrial Park Management Committee to undertake administrative assistance management tasks because he are familiar and fast in business and have outstanding management capabilities.

In order to gain a deeper understanding of students' satisfaction with the modern apprenticeship model, we did a survey of students. One of the questions was an open question, the topic was: "What do you think modern apprenticeship classes can help you the most? The answer to this question is surprisingly concentrated in a few, such as: solved employment, solved family financial difficulties, gained knowledge and skills, and went to university. Figure 1 is a scale diagram of survey results.

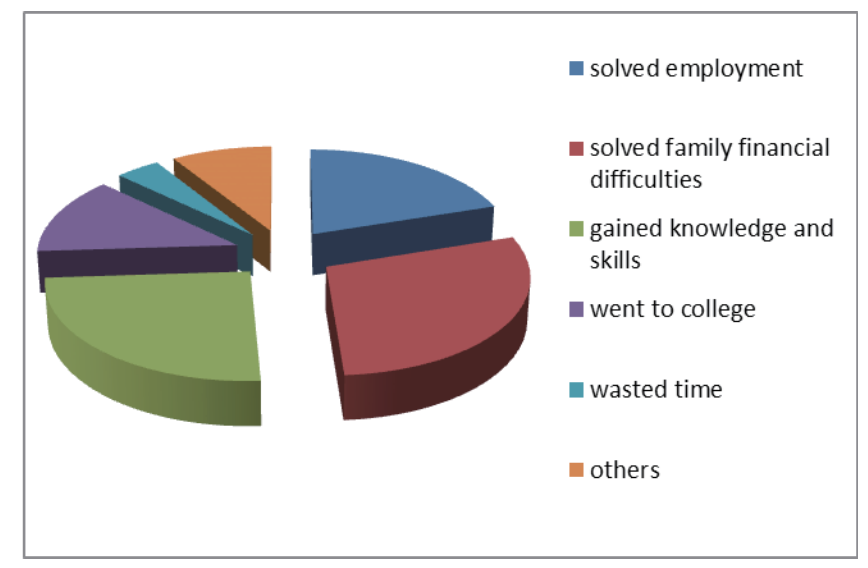

Figure 1 scale of survey results

It can be seen from the results in Figure 1 that the students as a whole are positive towards the modern apprenticeship school-running model. Most people think that the class has solved employment or has promoted his ability, which is consistent with the original intention of the class. There are also a small number of students who think that the class wasted their time. Upon closer inspection, it was found that some students who had poor learning effects were assigned to the big data annotation processing business department by the company. They did the same work as their secondary vocational classmates, and thought they can do this job without going to the modern apprenticeship class. 


\section{Conclusion}

The exploration and successful implementation of the modern apprenticeship has resulted in the following conclusions: (1) In the process of poverty alleviation through education, the guidance and policy support of the government are essential to ensure the initiative of enrollment and toe ensure the quality of the source of students in this class; (2) The school and the enterprise jointly formulate a training plan to ensure that the needs of the enterprise are highly compatible with the training path of the school, which is the key to the success of the modern apprenticeship class of computer application technology; (3) The company's business level plays a pivotal role for the growth of students. In order to improve the achievement of students in the modern apprenticeship training model, in the future, it is planned to improve the technical content of the company in big data processing, and strive to make all students in the class have a gain.

\section{References}

[1] Opinions of the Ministry of Education on Carrying out the Pilot Work of Modern Appr enticeship,Jiaozhoucheng[2014]No.9, http://old.moe.gov.cn/publicfiles/business/htmlfiles/moe/ s7055/201409/174583. html

[2] Zhang Ronggui, Xu Bingzhao. The problems and countermeasures of the school-enterprise mixed running school based on the modern apprenticeship pilot program_- Taking the automobile major of Fujian Vocational College of Shipping Administration as an example [J]. Mechanical and Electrical Technology, 2019 (06): 114-117.

[3] Liu Ruiyao. Research on the Reform of Applied Undergraduate Cross-border E-commerce Talent Training Model Based on Modern Apprenticeship_-Taking the International Trade Major of Zhejiang University of Finance and Economics as an example [J]. Operation and Management, 2020(07): 102-106

[4] Pan Xiuqiang, Pan Yiting, Jin Huifeng. A training model for information professionals under the background of "Internet +"[J]. Computer Education, 2017, (05): 34-37.

[5] Pan Yiting, Pan Xiuqiang, Jin Huifeng, et al. Discussion on Modern Apprentice Education Model Based on the Interactive Ecosphere of School City[J]. Computer Education, 2017(3):81-83,87.

[6] Wu Jianshe. Five major problems to be solved urgently in the implementation of modern apprenticeship in higher vocational education[J]. Higher Education Research, 2014(7):41-45.

[7] Xie Junhua. Discussion on the modern apprenticeship talent training model in higher vocational colleges [J]. Vocational Education Forum, 2013(16): 24-26. 